\title{
43. Dreiländertreffen 2019 in Mainz
}

Liebe Kolleginnen und Kollegen,

unser Jahreskongress, das 43. Dreiländertreffen der DEGUM, ÖGUM und SGUM, findet dieses Jahr vom 16.10.-19.10.2019 in der Rheingoldhalle in Mainz statt. Zum größten Ultraschall-Meeting Europas möchten wir Sie wieder herzlich einladen.
Es wartet auf Sie Interessantes und Neues aus allen klinischen Einsatzbereichen des Ultraschalls.

Die Kongressanmeldung läuft bereits und Sie können sich Ihren Frühbucherrabatt jetzt schon sichern.

Die Einreichung Ihres Abstracts ist bis zum 15.04.2019 möglich. Wir freuen uns sehr auf Ihre Beiträge.
Alle weiteren Informationen erhalten Sie unter https://www.ultraschall2019.de

Wir freuen uns auf Sie!

Ihre diesjährigen Kongresspräsidenten

Prof. Markus Hahn

Dr. Hans-Peter Weskott 